\title{
Quantification and Analysis of Uncertainties in Parameters of Rotors Supported by Bearings
}

\author{
Caio C. O. da Costa and Cesar da Costa
}

\begin{abstract}
Rotating unbalance is one of the most important critical parameters that causes operational failures of rotating machinery. The uneven distribution of mass on the structure of the rotors creates heavy spots, which must be eliminated to avoid generating excessive stress on the rotor bearings. The main objective of this work is to perform the uncertainty analysis on rotating machine systems supported with rolling bearings. A computational procedure is implemented to achieve this objective that can qualitatively represent the main behaviors and parameters of rotating machines. Further, methods of uncertainty quantification are applied to verify the behavior of the system given the probability density functions of the input parameters. One of the most commonly used methods is the Monte Carlo method, which requires thousands of simulations to produce accurate results. This method is used to obtain means and standard deviations of the system responses, given the means and standard deviations of the inputs. In our work, Monte Carlo simulation has been successfully used as a reference stochastic solver to evaluating the variability of the dynamic responses.
\end{abstract}

Index Terms - Monte Carlo method, Quantification of uncertainty, Rotors, Rotating machines, Uncertainty analysis, Unscented Transform.

\section{INTRODUCTION}

Rotary machine is one of the main types of machinery used in contemporary world for various applications. Generally, this type of machinery is used for energy production, fluid transportation, food processing, and several other purposes and it has become an integral part in any industrial sector. So, it is vitally important to have a deep knowledge and a better understanding of how it works. Rotating machines are mechanical equipment that work by rotating around an axis. Pumps, turbines, gearboxes, compressors, engines are some examples of these types of equipment [1], [2].

During the operation of rotating machines, the bearings are the components that will restrict and regulate the movement of the shaft and, consequently, will be responsible for the damping and the rigidity of the system. Some of the important types of bearings are sliding, rolling, hydrodynamic, hydrostatic, electromagnetic, and aerostatic [3], [4].

Liao [5] published a study in 2002 on a bearing subjected to high speeds and axial and radial loads which analyzed the consequences of centripetal force. Various other parameters involved in the dynamics of the bearing were determined through dimensional analysis and balance of forces, and he

Submitted on January 29, 2020.

Published on February 15, 2021.

C. C. O. Costa, Mechanical Department, Universidade Estadual de Campinas, Brasil.

(e-mail: caiocesarcosta2008@gmail.com) concluded that it is necessary to increase the contact area in the axial direction to avoid slipping.

Changqing [6] carried out a study in 2006 in which a rotor was subjected to high rotations, supported on ball bearings, with clearance between raceways and balls, and ripples on the raceway. The study indicated that clearance, preload, and loading strongly affect the stability of the system significantly.

Jedrzejewski et al [7] published an article Modeling of angular contact ball bearings and axial displacements for high-speed spindles in 2010. In this article Jedrzejewski conducted a dynamic analysis of an angular contact ball bearing and analyzed the effects of centripetal force and gyroscopic moments when it operated at high speeds. The main objective of the article is to contribute to the development of high precision systems, in which the displacement caused by deformations of the shaft and bearings were perfectly described.

Many problems in rotating systems can be attributed to the design and application of the bearings according to Vance et al. [8]. Thus, understanding the physical phenomena of the bearings and their functions is essential to improve the dynamic performance of the system.

Currently, one of the most important parts of a mechanical design is using and performing simulations to study the behavior of a machine as close to real-time applications as possible before manufacturing it. Koroishi et al. [9] represented and analyzed the uncertainties in the rotor parameters by using Gaussian homogeneous stochastic fields discretized by Karhunen-Loève expansion; the dynamic response of the system with random parameters was characterized through Hypercube Latin sampling and Monte Carlo simulation.

Through the realization of these simulations, it is also possible to simulate the instability factors acting on the project by varying the numerical values used in certain quantities that are influenced by sources of uncertainty [10], [11]. The study of instability and uncertainties in a project through simulations is especially important, since these analyses allow a better understanding of the disturbing factors that can mostly affect the system's behavior. Once these factors are determined in the simulations, it is possible to adapt the system to reduce the instabilities as much as possible, getting the result as close as possible to the desired ones [12], [13].

C. Da Costa, Automation and Control Department, Federal Institute of São Paulo, Brasil.

(e-mail: ccosta@ifsp.edu.br) 
This paper deals with the analysis and quantification of uncertainties in rotating systems supported on bearings using the Monte Carlo method combined with mathematical models. The proposed computational procedure was performed using MATLAB software, which allowed simulating models of different types of rotors. The Monte Carlo method was implemented to solve stochastic problems.

This paper is organized as follows. Section 2 describes rotor system model, Jeffcott rotor, Campbell diagram, and quantification of uncertainties. Section 3 we present materials and methods used in this work. Section 4 presents results and discussions. Section 5 presents concluding remarks.

\section{ROTOR SYSTEM MODEL}

\section{A. Jeffcott Rotor}

Modeling a mechanical system, whatever it may be, requires knowledge of the real system and simplifications that can be made to create an effective mathematical model. It is also known as Laval Rotor, the Jeffcott Rotor is a more elaborate model that highlights the existence of various critical speeds in rotors and consists of an unbalanced hard disc mounted on the middle of the extension of a flexible shaft of negligible mass supported by rigid bearings, as shown in Fig. 1.

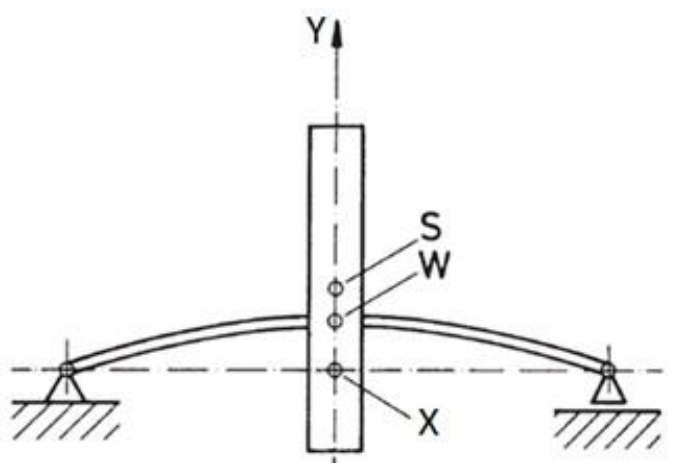

Fig. 1. Jeffcott Rotor.

According Cavalini Jr. et al [11] the matrix differential equation that model the dynamic behavior of a flexible rotor supported by fluid film bearings is represented by the Eq. 1 . given below.

$M \ddot{q}+\left[D+\Omega D_{g}\right] \dot{q}+\left[K+\dot{\Omega} K_{s t}\right] q=W+F_{u}+F_{h}$

where:

$M$ is the mass matrix.

$D$ is the damping matrix (proportional damping).

$D_{g}$ represents the gyroscopic effect.

$K$ is the stiffness matrix.

$K_{s t}$ is the stiffness matrix resulting from the transient motion.

All these matrices are related to the rotating parts of the system, such as couplings, discs, and the shaft.

The vector $q$ contains the generalized displacements and $\Omega$ is the shaft rotation speed. Further, Wrepresents the weight of the rotating parts, $F_{u}$ denotes the unbalance forces, and $F_{h}$ represents the vector of the shaft supporting forces produced by the hydrodynamic bearings.

\section{B. Campbell Diagram}

The Campbell diagram is used to analyze the behavior of the rotor models proposed in our work. The Campbell diagram presents the behavior of the system's natural frequency as a function of its rotation speed. Campbell's diagram consists of curves that reveal how the natural frequency of the system changes as a function of the frequency of rotation of the rotor. This diagram can be obtained analytically by calculating the eigenvalues of the system's free movement Equation 1 as a function of rotation. Fig. 2 presents an example of a Campbell diagram.

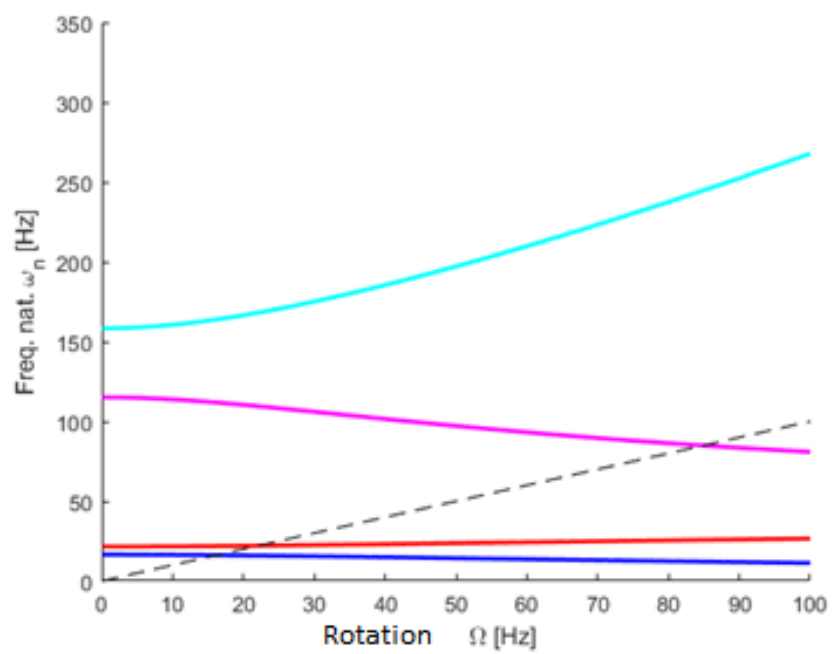

Fig. 2. Campbell diagram.

\section{Quantification of Uncertainties}

Stochastic modeling was used and essential for quality control in industries and a new type of project emerged that takes into account uncertainties. When the parameters of a system are considered as random ones, then their response will also be random depending on the stochastic model used to modeling the parameters. The Monte Carlo Method is easy to implement and so it is generally used to solve stochastic problems [10], [14], [15]. According to Zvyagin [16], the Monte Carlo method consists of:

(i) Generating random samples for the known (input) variables of the problem;

(ii) Calculating the system response for each set of input variables;

(iii) Analyzing the convergence of the answer;

(iv) Obtain statistical information (distribution, mean, variance, symmetry, kurtosis) of the answer variable.

The Monte Carlo method randomly generates values for all parameters of the problem, which are random variables in the probabilistic analysis. A deterministic analysis is conducted with these values, and their results, which are also considered as random variables, are stored. This process is repeated many times to achieve maximum number of possible combinations. A statistical summary of the results obtained is made after many simulations. The frequency of these results determines a probabilistic function (density function) that represents the probabilities of occurrence of these results [17], [18].

It should be noted that this method can be applied only when the parameters are statistically independent, that is, the 
value assigned to a parameter does not affect the allocation of values to other parameters in any manner. It is also observed that, although the assignment of values to the parameters happens at random, it follows the mechanisms of probability of occurrence. It is important to note that these mechanisms represent the uncertainties associated with the parameters through probabilistic functions [17]-[19], [21], [22].

\section{MATERIALS AND METHODS}

The proposed uncertainty analysis was applied to three different rotor models: (i) the Jeffcott rotor with the decentralized disc and flexible bearings; (ii) the Jeffcott rotor with unbalanced disc and flexible bearings; and (iii) the Jeffcott rotor with centralized disc and hydrodynamic bearings.

For all the three models to be analyzed, the variables (i) material's density and (ii) Young's modulus were adopted or used as random. Fig. 3 presents the block diagram of the algorithm that performs the Monte Carlo simulation, computation of the natural frequencies, the damping of the system, and the speed of stability limits.

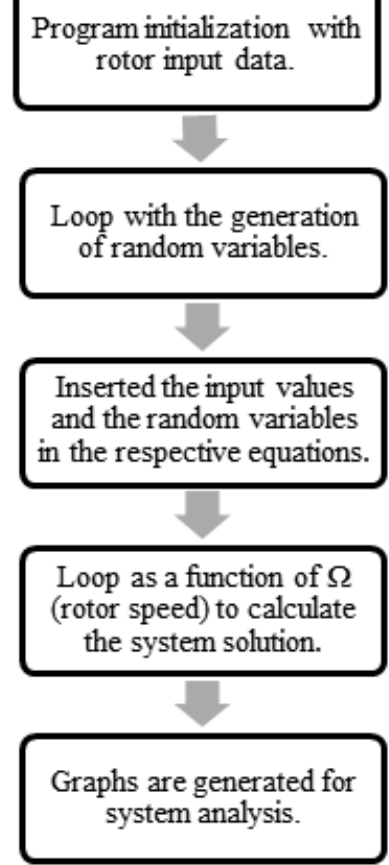

Fig. 3. Block diagram of algorithm implemented in MATLAB software.

The algorithm was implemented using the MATLAB software and the following procedure is adopted for implementation:

Program initialization with rotor input data: Here, the system input data is first stated. The stated input values are scalar and constant during the simulation. The input values consist of number of iterations, length and diameter of the shaft, length and diameter of the bearings, range of the analyzed rotation speed.

Loop with the generation of random variables: Using a random variable generator this loop assigns value to the material's density and the Young's modulus. It is highly important to note that all the next steps occur within this loop, for each of the material's density values and Young's modulus. This loop will occur as long as the number of interactions needed to perform the Monte Carlo simulation.

Inserted the input values and the random variables in the respective equations: Within the loop of the random variables, the constant input values of the system, the material's density and, Young's modulus are introduced in the equations that are used to solve the system depending on the model of rotor being simulated and the data to be obtained (natural frequency, damping, and stability limit speed).

Loop as a function of rotation speed $(\Omega)$ to calculate the system solution: This loop solves the equation as a function of rotation speed $(\Omega)$.

Graphs are generated for system analysis: The respective graphs are generated (Campbell diagram, damping graph and stability limit graph) at the final stage.

\section{RESUlTS AND DisCUSSIONS}

\section{A. The Jeffcott Rotor with Decentralized Disc and Flexible Bearing}

The first model analyzed is the Jeffcott rotor with the decentralized disc and flexible bearings. Table 1 represents the parameters used for the simulations.

TABLE I: PARAMETERS DECENTRALIZED DISC

\begin{tabular}{cc}
\hline \hline Parameter & Value \\
\hline Shaft diameter $[\mathrm{m}]$ & 0.45 \\
Shaft length $[\mathrm{m}]$ & 4 \\
Distance a $[\mathrm{m}]$ & 1 \\
Distance b $[\mathrm{m}]$ & 3 \\
Bearing stiffness $\mathrm{kA}_{1}[\mathrm{~N} / \mathrm{m}]$ & $9.03 \times 10^{8}$ \\
Bearing stiffness $\mathrm{kA}_{2}[\mathrm{~N} / \mathrm{m}]$ & $3.04 \times 10^{8}$ \\
Bearing stiffness $\mathrm{kB}_{1}[\mathrm{~N} / \mathrm{m}]$ & $3.06 \times 10^{8}$ \\
Bearing stiffness $\mathrm{kB}_{2}[\mathrm{~N} / \mathrm{m}]$ & $5.82 \times 10^{8}$ \\
Bearing clearance $[\mu \mathrm{m}]$ & 90 \\
Viscosity $\left[\mathrm{Pa}^{\mathrm{s}} \mathrm{s}\right]$ & 0.04 \\
Disc volume $\left[\mathrm{m}^{3}\right]$ & 1 \\
\hline \hline
\end{tabular}

Fig. 4 and 5 present the Campbell and damping factor graphs for a deterministic model of the rotor with a decentralized disc, considering a disc with a mass of $7.8 \times 10^{3} \mathrm{~kg} / \mathrm{m}^{3}$ and Young module of $200 \mathrm{GPa}$.

In the Campbell diagram shown in Fig.4, it is possible to note that the line indicating the first harmonic excitation intercept the curves at three points. These points represent the first three critical speeds. The first critical speed of this model is $29 \mathrm{~Hz}(1740 \mathrm{rpm})$, the second speed is $32.9 \mathrm{~Hz}(1974 \mathrm{rpm})$, and the third is $36.4 \mathrm{~Hz}(2184 \mathrm{rpm})$. It is important to note that, the difference between these three critical speeds is not so large and hence, the analysis for the stochastic model presented will be made only for the first critical speed.

It is possible to observe from the graph in Fig. 4 that the natural frequency curves tend to meet for rotations above $20 \mathrm{~Hz}$, which results in overlapping of the curves for multiple iterations. Due to the proximity of these three curves, it can be observed that when the rotation is performed in the range between these curves in an operating system, and then it will be difficult for it to attain the resonance of the system. This shows that there is a great need for carrying out computer simulations for real systems to determine the best way to operate the system. From the damping factor graph in Fig. 5, it is observed that the damping factor tends to decrease after the rotation at $40 \mathrm{~Hz}$ for all simulated objects. 


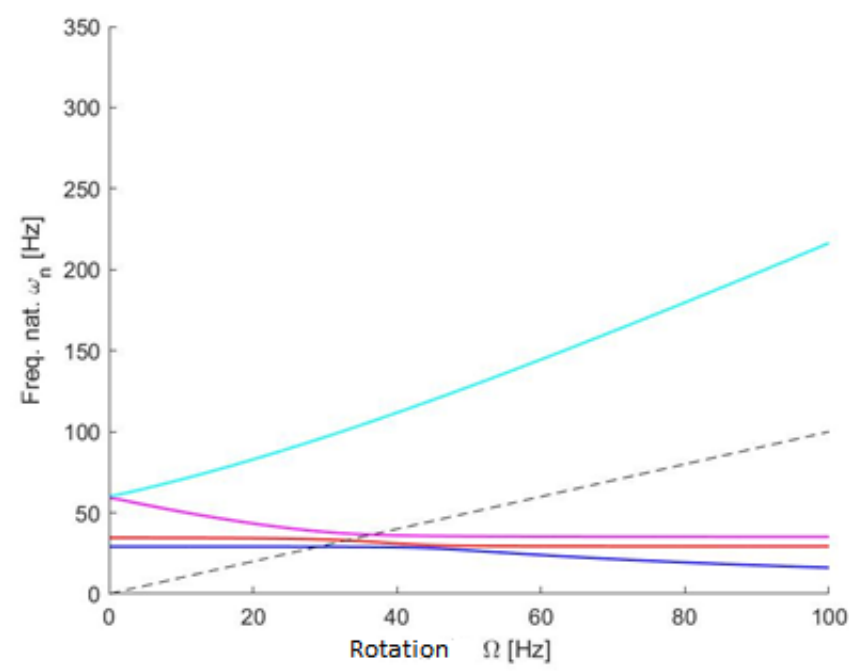

Fig. 4. Campbell graphs for deterministic parameters of a rotor with a

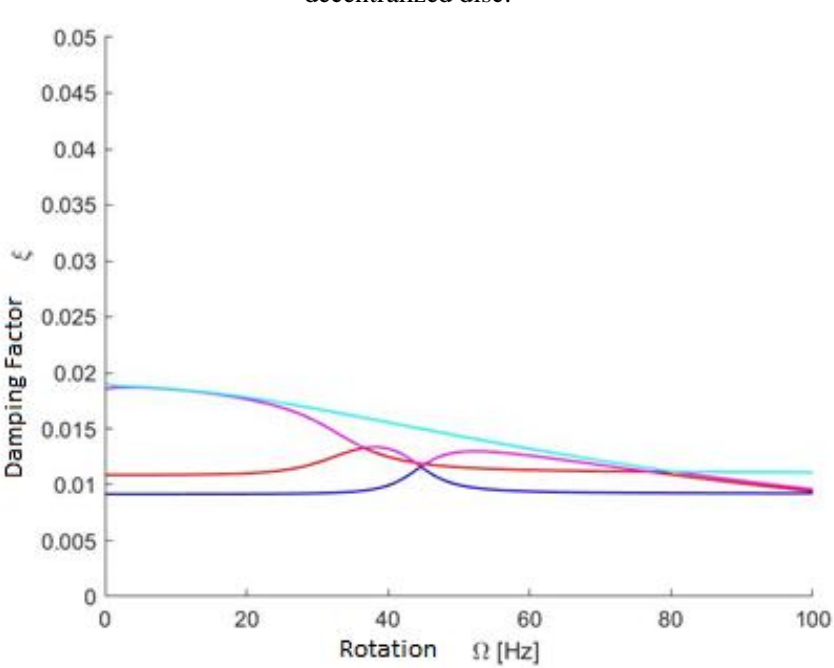

Fig. 5. Damping factor graph for deterministic parameters of a rotor with a decentralized disc.

Further, the values for material's density and Young's modulus were generated randomly based upon the gamma distribution. Four tests were performed with the uncertainty levels of these variables corresponding to the variation coefficients of $5 \%$ and $10 \%$, as presented in Table 2 .

Further, simulations were performed with 4000, 6000, and 8000 objects for the stochastic model of the rotor with a decentralized disc based on the tests in Table 2 to find how many objects would be necessary for the results to converge.

Fig. 6 displays the results with greater convergence that is achieved by simulating 8000 objects. Therefore, for the analyzed stochastic model, 8000 objects were considered for each of the proposed tests. Using the simulations, the critical velocities were obtained for each of the tests in Table 2 .

\begin{tabular}{ccc}
\multicolumn{3}{c}{ TABLE II: COEFFICIENTS OF VARIATION } \\
\hline \hline Test & $\begin{array}{c}\text { Material's } \\
\text { Density }\end{array}$ & $\begin{array}{c}\text { Young's } \\
\text { Modulus }\end{array}$ \\
\hline 1 & $5 \%$ & $5 \%$ \\
2 & $5 \%$ & $10 \%$ \\
3 & $10 \%$ & $5 \%$ \\
4 & $10 \%$ & $10 \%$ \\
& & \\
\hline \hline
\end{tabular}

The mean, variance, asymmetry, and kurtosis of the critical velocity were calculated to analyze the effect of the variation in material's density and Young's modulus.

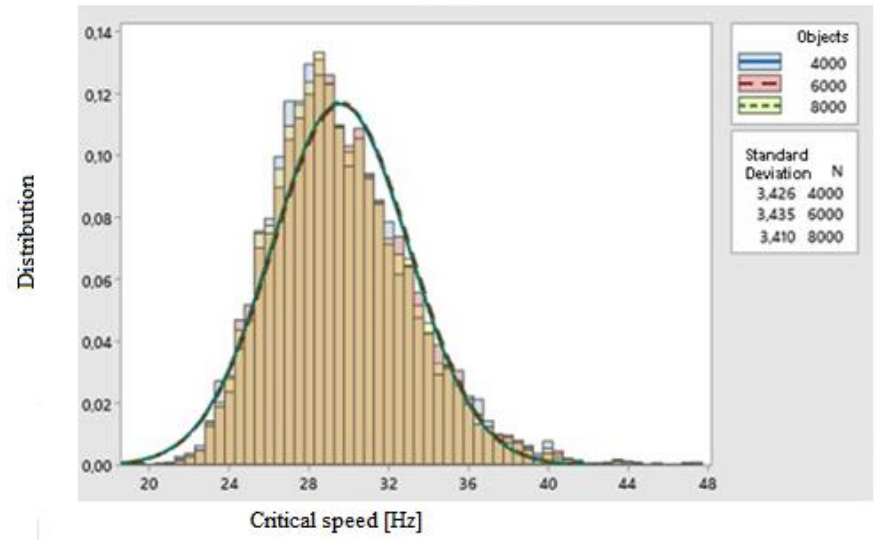

Fig. 6. Histogram of critical speeds for 4000, 6000, and 8000 objects.

The results are presented and discussed in the following sections:

Critical speed mean: It is found that the variation in the material's density coefficient has little influence on the mean of the critical speeds. In addition, the variation of the young's module coefficient has no significant influence on the critical speed mean.

Critical speed variance: It is observed that the variation in the material's density coefficient is directly proportional to the variation in critical speed variances. The variation of the young's module coefficient does not have any significant influence on the critical speed variances.

Critical speed Asymmetry: It is found from the tests that the coefficient of variation of $10 \%$ of the material's density is more asymmetric than 5\%. In addition, it is observed that the variation of the Young's module coefficient has a small influence on the asymmetry of the critical speed.

Critical speed kurtosis: It is found out those tests with a $10 \%$ variation in material's density coefficients show a higher kurtosis value than a $5 \%$ variation. Note that the variation of the Young's module coefficient does not have any influence on Kurtosis at all.

\section{B. The Jeffcott Rotor with Unbalanced Disc and Flexible Bearings}

The second model analyzed is the Jeffcott rotor with unbalanced disc and flexible bearings. Table 3 shows the parameters used for the simulations.

\begin{tabular}{cc}
\multicolumn{2}{c}{ TABLE III: PARAMETERS UNBALANCED DISC } \\
\hline \hline Parameter & Value \\
\hline Shaft diameter $[\mathrm{m}]$ & 0.45 \\
Shaft length $[\mathrm{m}]$ & 4 \\
Distance a $[\mathrm{m}]$ & 0,8 \\
Distance $\mathrm{b}[\mathrm{m}]$ & 3 \\
Bearing stiffness $\mathrm{kA}_{1}[\mathrm{~N} / \mathrm{m}]$ & $3.33 \times 10^{8}$ \\
Bearing stiffness $\mathrm{kA}_{2}[\mathrm{~N} / \mathrm{m}]$ & $6.67 \times 10^{8}$ \\
Bearing stiffness $\mathrm{kB}_{1}[\mathrm{~N} / \mathrm{m}]$ & $0.83 \times 10^{8}$ \\
Bearing stiffness $\mathrm{kB}_{2}[\mathrm{~N} / \mathrm{m}]$ & $1.67 \times 10^{8}$ \\
Bearing clearance $[\mu \mathrm{m}]$ & 90 \\
Viscosity $\left[\mathrm{Pa}^{8} \mathrm{~s}\right]$ & 0.04 \\
Disc volume $\left[\mathrm{m}^{3}\right]$ & 1 \\
\hline \hline
\end{tabular}


Fig. 7 and 8 present the Campbell and damping factor graphs, respectively, for a deterministic model of the rotor with an unbalance disc, using a disc with a mass of $7.8 \times 10^{3} \mathrm{~kg} / \mathrm{m}^{3}$ and Young's module of $200 \mathrm{GPa}$.

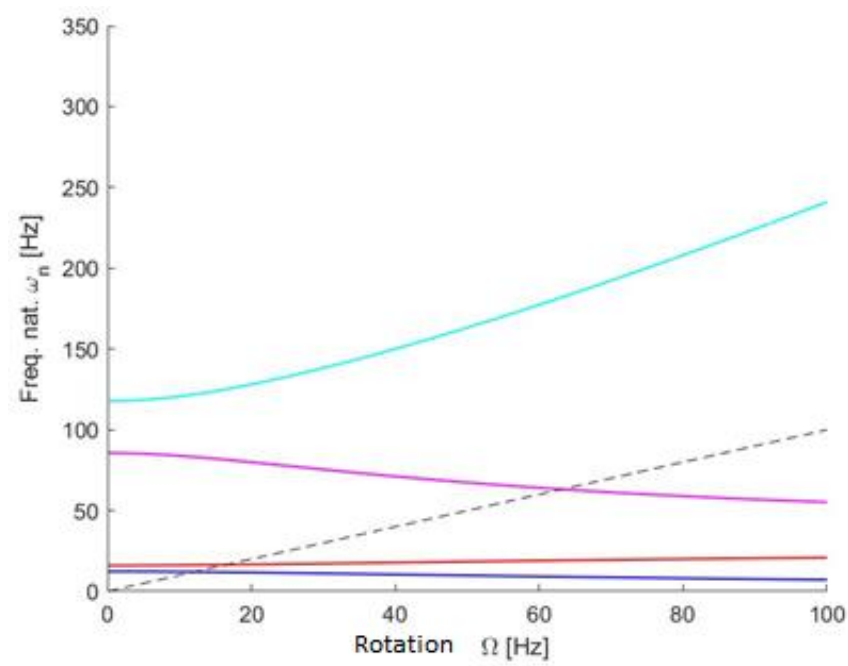

Fig. 7. Campbell's graph for deterministic parameters of the rotor with an unbalance disc.

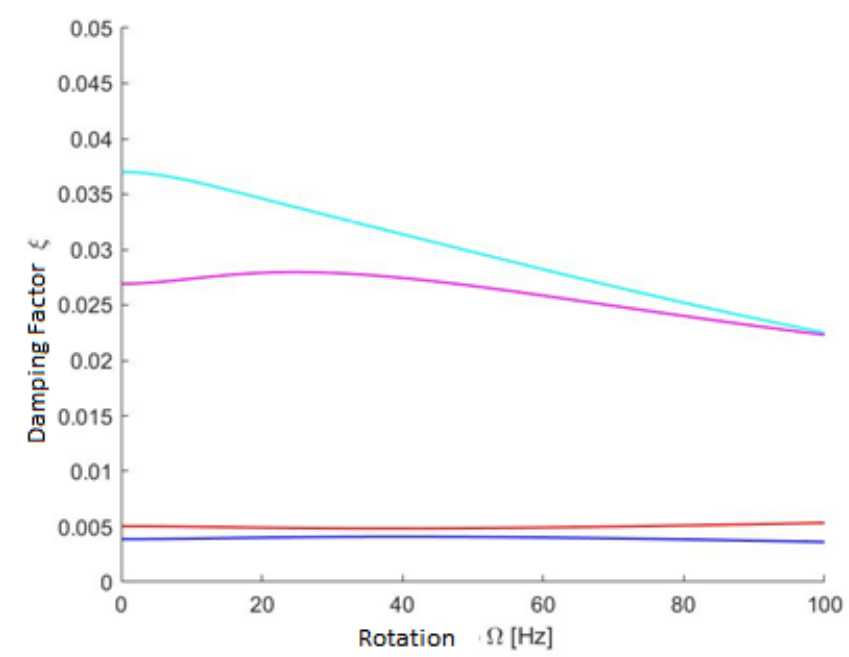

Fig. 8. Graph of the damping factor for deterministic parameters of a rotor with an unbalance disc.

It is possible to observe in the Campbell diagram shown in Fig. 7 that the line indicating the first harmonic excitation intercepts the curves of the Campbell diagram at three points. These points represent the three critical speeds. The first critical speed of this mode is $12 \mathrm{~Hz}(720 \mathrm{rpm})$, the second speed is $16.4 \mathrm{~Hz}(990 \mathrm{rpm})$, and the third is $63.2 \mathrm{~Hz}(3792$ $\mathrm{rpm})$. In this model, the difference between the first two critical speeds is not so significant; however, they have a much lower value than the model with a decentralized disc. But the third critical speed is much higher than the other two speeds and also much higher than the third critical speed obtained in the model with a decentralized disc. As the value of the third critical speed is very high, reaching that point (speed) will be difficult during operation. Since the values of the first and second speed are very close, the analysis for the stochastic model presented below will be performed only for the first critical speed.

Further, simulations were performed with 4000, 6000, and 8000 objects for the stochastic model of the unbalance disc rotor based on tests in Table 2 to determine how many objects would be necessary for the results to converge. Figure 9 presents a histogram with the critical speeds obtained with simulations.

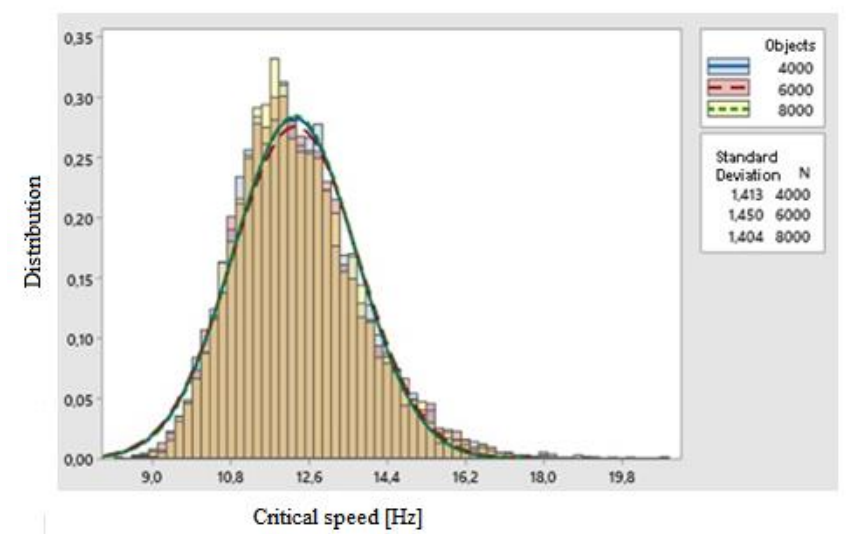

Fig. 9. Histogram of critical speeds for 4000, 6000, and 8000 objects.

Further, the mean, variance, asymmetry, and kurtosis of the critical speed were calculated to analyzing the influence of the variation in material's density and Young's modulus. The results presented are similar to those results obtained with the rotor with the decentralized disc and flexible bearings.

C. The Jeffcott Rotor with Centralized Disc and Hydrodynamic Bearings

The Jeffcott rotor is the last model analyzed, which has a disc centered and supported by hydrodynamic bearings. In this model, bearing modeling for a flexible shaft and the influence of the rotation speed on the bearing stiffness coefficient were considered. The parameters used for the simulations are presented in Table 4.

The analysis of Campbell's diagram and critical speeds were first performed for this model. After that, load curves, stability limit curves, and the behavior of limit speeds were analyzed.

\begin{tabular}{cc} 
TABLE IV: PARAMETERS HYDRODYNAMIC BEARINGS \\
\hline \hline Parameter & Value \\
\hline Shaft diameter $[\mathrm{m}]$ & 0.45 \\
Shaft length $[\mathrm{m}]$ & 4 \\
Bearing radius $[\mathrm{m}]$ & 0.75 \\
Bearing length $[\mathrm{m}]$ & 0.075 \\
Bearing clearance $[\mu \mathrm{m}]$ & 90 \\
Viscosity $[\mathrm{Pa} . \mathrm{s}]$ & 0.04 \\
Disc volume $\left[\mathrm{m}^{3}\right]$ & 1 \\
\hline
\end{tabular}

\section{Campbell's Diagram and Critical speeds}

Fig. 10 and 11 present the Campbell and damping factor graphs, respectively, for a deterministic model of the rotor with centralized disc and hydrodynamic bearings, considering a disc with a mass of $7.8 \times 10^{3} \mathrm{~kg} / \mathrm{m}^{3}$ and Young's module of $200 \mathrm{GPa}$.

It is possible to observe from the Campbell diagram shown in Figure 10 that the line indicating the first harmonic excitation intercepts the curves of the Campbell diagram at two points. These points denote the first two critical speeds. The first critical speed of this model is $28 \mathrm{~Hz}(1680 \mathrm{rpm})$, the second speed is $29.3 \mathrm{~Hz}$ (1758 rpm). It is important to note that the first two critical speeds for this model are very close, 
with a difference of only $1.3 \mathrm{~Hz}(78 \mathrm{rpm})$, a much lower value than the previous models shown.

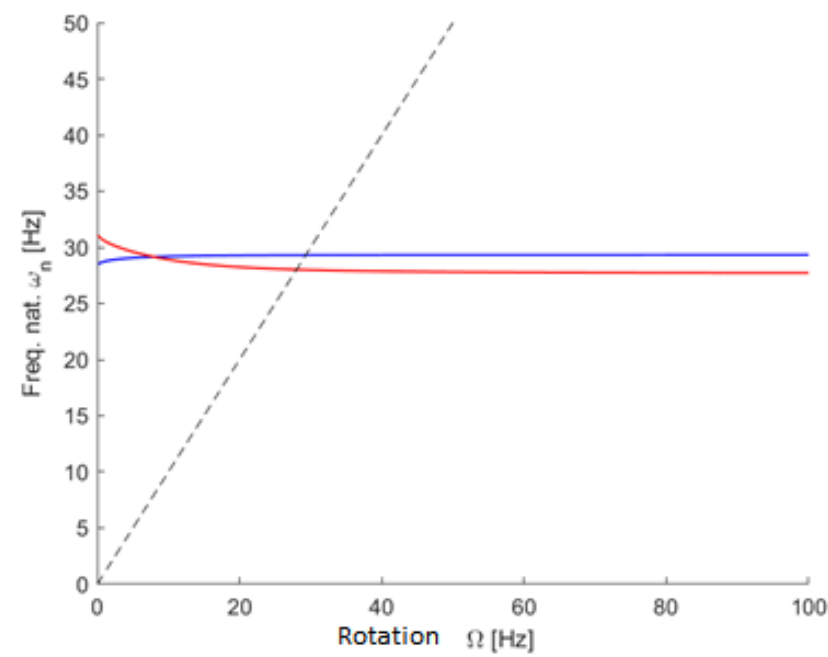

Fig. 10. Campbell plot for deterministic parameters of a hydrodynamic bearings.

Because of the close proximity between the critical speeds, it has been decided to perform the analysis of the stochastic models only for the first critical speed.

It can be observed from the simulation that for speeds above $20 \mathrm{~Hz}$, the natural frequency becomes practically constant for all simulations performed on this model. This behavior cannot be observed in either of the other two models. It was also found out that the damping factor becomes almost constant after $20 \mathrm{~Hz}$.

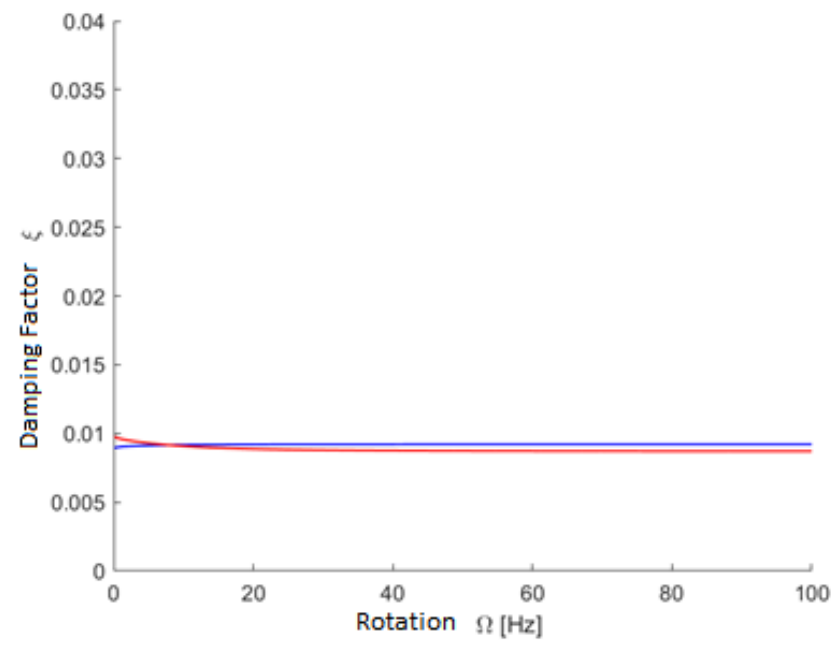

Fig. 11. Damping factor graph for deterministic parameters of a hydrodynamic bearings.

\section{Stability Limit and Load Curves}

Further, the same data as in Table 2 was considered to conduct the modeling and analysis of the stability limit of the rotor with centered disc and hydrodynamic bearings. Fig. 12 displays a graph of the stability limit and load curve for a deterministic model, considering a mass disk $7.8 \times 10^{3} \mathrm{~kg} / \mathrm{m}^{3}$ and a Young's modulus of $200 \mathrm{GPa}$. Note that the dashed curve indicates the stability limit curve while the continuous curve indicates the load curve in the graph. It is found that the speed limit value of stability is $57.2 \mathrm{~Hz}(3432 \mathrm{rpm})$ for this deterministic model. It is possible to note that the limit speed of stability is much higher than the first two critical speeds of the same model. It is also important to note that when the limit speed of stability is reached, the eccentricity coefficient has a very low value, close to 0.08 when compared to other models.

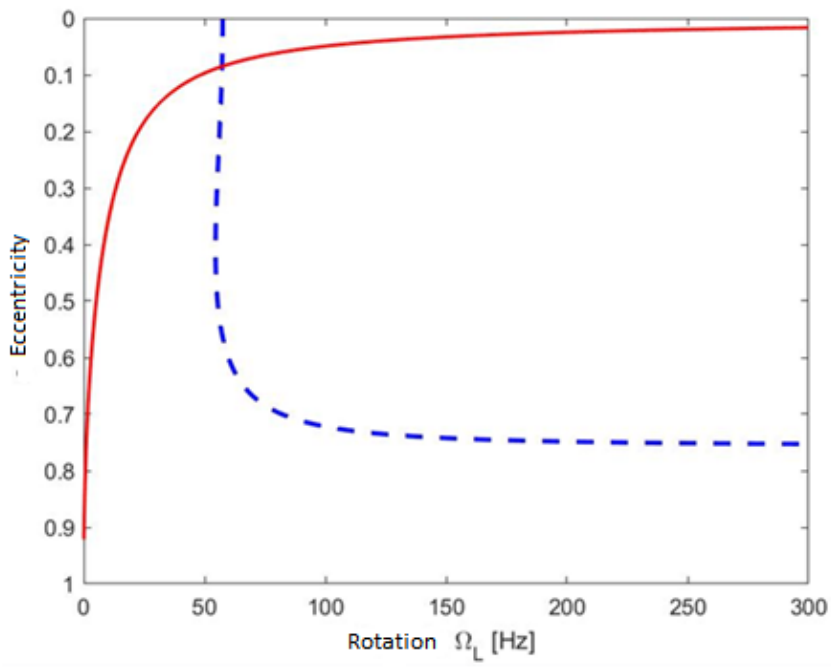

Fig. 12. Load curve (continuous) and stability limit curve (dashed) for deterministic parameters of a rotor with hydrodynamic bearings.

Further, simulations were performed for the analysis of the critical speeds for the stochastic model of the rotor with centered disc and hydrodynamic bearings. The values for material's density and Young's modulus were generated randomly based upon the gamma distribution. Four tests were also considered, with the uncertainty levels of these variables corresponding to the variation coefficients of $5 \%$ and $10 \%$, as presented in Table 2. Fig. 13 displays a histogram with the critical speeds obtained in the simulations.

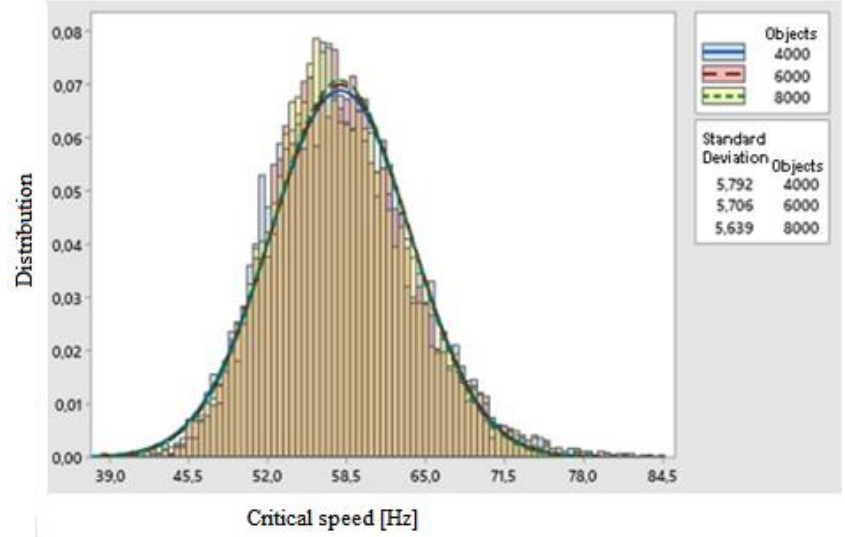

Fig. 13. Histogram of the limit speeds for 4000,6000 , and 8000 objects.

The histogram in Fig. 13 shows that the results with the greatest convergence are obtained in the simulation of 8000 objects. Fig. 14 shows the graph of the load curve and stability limit for the tests. It is possible to observe from the graph that both the load and the stability limit curves varied for each of the simulated objects. This is in accordance with the literature [21], [22], because for the model analyzed, the density influences both the load curve and the stability limit curve. But the Young's modulus influences only the stability limit curve. This shows how both variables are important for the analysis of stability limit speeds. 
The stability transition zone is the area of the graph where the two curves intersect and in this model this zone occurs for rotations between $40 \mathrm{~Hz}$ and $85 \mathrm{~Hz}$. It can also be found out that for speeds above $200 \mathrm{~Hz}$, the eccentricity coefficient has a value very close to 0 . This indicates that for speeds above $200 \mathrm{~Hz}$, the shaft is very close to the center of the bearing.

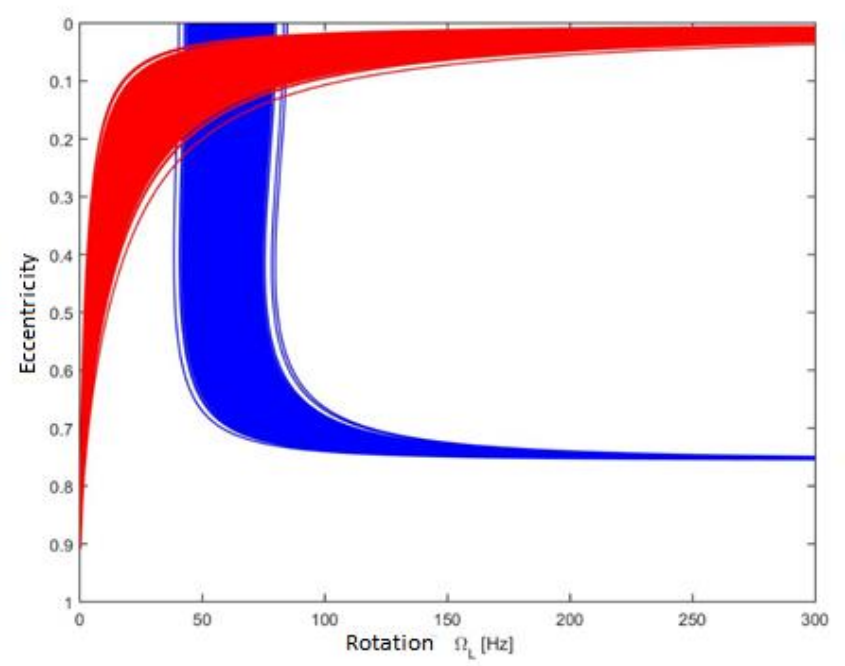

Fig. 14. Load curve (red) and stability limit curve (blue) for stochastic parameters of a centered disc rotor.

The mean, variance, asymmetry, and kurtosis of the critical velocity were calculated to analyzing the influence of the variation in density and Young's modulus.

During the analysis of the limit speed of stability, it was observed that the influence of the variation of the density coefficient is directly proportional to the variation of the mean of the limit speed. However, it is also observed that the variation of Young's modulus has insignificant influence on the means.

When the variance is considered, it was observed that the variation in the density variation coefficient is directly proportional to the variation in variance and the variation in the Young's modulus is inversely proportional but has a lesser influence than density variation.

When both asymmetry and kurtosis are considered, it was found that the variation in the coefficients of both density and Young's modulus do not have any significant influence on critical velocities.

\section{CONCLUSION}

The aim of this work is to investigate and analyze the uncertainties in different models of rotors using the Monte Carlo method. Three models of rotating systems were considered: a rotor with a decentralized disc and flexible bearings, a rotor with an unbalance disc and flexible bearings, and a rotor with a centered disc and hydrodynamic bearings.

Campbell diagrams, damping factor graphs, and stability limit graphs were obtained for deterministic and stochastic responses from the simulated systems and were used to verify the natural frequencies, damping factors, critical speeds, and limit speeds for each of the systems. In addition, Young's modulus (E) and material's density $(\rho)$ were defined as random parameters.
Further, critical speeds and stability limits for the proposed models were determined for stochastic responses. Further, the influences and effects of random variables on the mean, variance, asymmetry, and kurtosis of each of the main data obtained were also analyzed. These are important results, since it allows a more adequate analysis to determine or verify the operation of real systems.

In all analyzes, 8000 objects were considered for each of the tests, and tests were performed with coefficients of variation of $5 \%$ and $10 \%$ for both material's density and Young's modulus, which resulted in four tests for each of the analyzes performed.

Thus, we can categorically state that this work verified the effect of variability of the material's density and the Young's module on the stability limit of three models of rotating systems modeled using the MATLAB software. It was found that both the material's density and the Young's module influence the stability limit, an influence that can have effect in the values of mean, variance, symmetry, or kurtosis, depending on the model.

\section{REFERENCES}

[1] S. A. Korpela, Principles of Turbomachinery. Hoboken: John Wiley \& Sons, Inc., 480 p, 2011.

[2] B. J. Hamrock, S. R. Schmid, B. Jacobson, Fundamentals of Machine Elements. $3^{\mathrm{a}}$. ed. Boston: McGraw-Hill Higher Education, 980 p, 2013.

[3] G. Genta, Dynamics of Rotating Systems, Springer, 660 p, 2015.

[4] J. S. Rao, History of Rotating Machinery Dynamics, Springer, 354 p, 2011.

[5] N. T. Liao, "Ball bearing skidding under radial and axial loads". Mechanism and Machine Theory. Vol. 37, p. 91-13,2002.

[6] B. Changqing, "Dynamic model of ball bearings with internal clearance and waviness". Journal of Sound and Vibration, Vol. 294, p. 23-48, 2006.

[7] J. Jedrzejewski, W. Kwasny, "Modeling of angular contact ball bearings and axial displacements for high-speed spindles", CIRP Annals - Manufacturing Technology, 59 (2010) 377-382, 2010.

[8] J. Vance, F. Zeidan, B. Murphy, Machinery vibration and rotordynamics. John Wiley \& Sons, Inc., 2010.

[9] E. H. Koroishi, A. A. Cavalini Jr., A. M. G. De Lima, V. Steffen Jr., "Stochastic modeling of flexible rotors". Journal of the Brazilian Society of Mechanical Sciences and Engineering 34: 597-603, 2012.

[10] A. Cunha Jr., R. Nasser, R. Sampaio, H. Lopes, K, Breitman, "Uncertainty quantification through the Monte Carlo method in a cloud computing setting". Computer Physics Communications, 185(5), 13551363, 2014.

[11] A. A. Cavalini Jr., F. A. Lara-Molina, P. T. Sales, E. H. Koroishi, V. Seffen Jr., "Uncertainty analysis of a flexible rotor supported by fluid film bearings". Latin American Journal of Solids and Structures, 12(8), 1487-1504, 2015.

[12] G. Y. Garoli, H. F. Castro, "Stochastic collocation approach for evaluation of journal bearing dynamic coefficients". Proceedings of the 3rd International Symposium on Uncertainty Quantification and Stochastic Modeling, Vol. 1, pp. 1- 10, 2016.

[13] G. Y. Garoli, H. F. Castro, "Stochastic collocation approach to evaluate the nonlinear response of a rotor". VIRM 11 - Vibration in Rotating Machinery, Vol.1, Manchester, United Kingdom, pp. $397-$ 406, 2016.

[14] D. C. Montgomery, G. C. Runger, Applied Statistics and Probability for Engineers. 6. ed. John Wiley \& Sons, p. 594-607, 2014.

[15] J. C. Walter, G. T. Barkema, "An introduction to Monte Carlo methods". Phisica: Statistical Mechanics and Its Applications, 418(15), 78-87, 2014

[16] L. S. Zvyagin, "Iterative and non-iterative methods of Monte Carlo as actual computing methods Bayesian analysis". 2017 XX IEEE International Conference on Soft Computing and Measurements (SCM), St. Petersburg, pp. 18-21, 2017.

[17] E. S. Cursi, R. Sampaio, "Uncertainty Quantification and Stochastic Modeling with MATLAB", Elsevier, ISTE Press, UK, 442 p, 2015.

[18] E. Peradotto, A. M. Panunzio, L. Salles, C. Schwingshackl, "Stochastic Methods for Nonlinear Rotordynamics with 
Uncertainties", Proceedings of ASME Turbo Expo, June 15-19, Montreal, Quebec, Canada, 2015.

[19] G. B. Daniel, L. C. Vieira, K. L. Cavalca, "Sensitivity analysis of the dynamic characteristics of thrust bearings". 3rd International Symposium on Uncertainty Quantification and Stochastic Modeling, Maresias, vol. 1, pp.1-10, 2016

[20] G. Chun-biao, W. Yue-hua, Y. Shi-xi, C. Yan-long, "Nonparametric modeling and vibration analysis of uncertain Jeffcott rotor with disc offset". International Journal of Mechanical Sciences, 78 (2014) 126134, 2014.

[21] A. A. Cavalini, A. D. G. Silva, F. A. Lara-Molina, V. Steffen, "Dynamic analysis of a flexible rotor supported by hydrodynamic bearings with uncertain parameters". Meccanica; 52, 2931-2943 (2017).

[22] S. Heindel, F. Becker, S. Rinderknecht, "Unbalance and resonance elimination with active bearings on a Jeffcott Rotor". Mechanical Systems and Signal Processing, 85 (2017) 339-353, 2017.

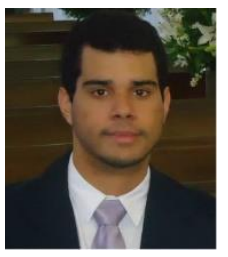

Caio Cesar O. da Costa was born in São Paulo, SP, Brazil. He received the B. SC degree in mechanical engineering from the UNICAMP - University of São Paulo State, SP, Brazil in 2019. His research interest includes rotors, rotating machines.

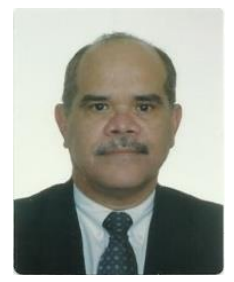

Cesar da Costa was born in Rio de Janeiro, RJ, Brazil. He received the B.Sc. degree in electronic and electrical engineering from the CEFET-RJ, Federal Center of Technological Education Center Celso Suckow da Fonseca and Nuno Lisboa University in 1975 and 1980 respectively. He received the M.Sc. degree in mechanical engineering from Taubate University, Taubate, SP, Brazil, and the Ph.D. degree in mechanical engineering from UNESP- Universidad Estadual Paulista Julio de Mesquita Filho, Guaratingueta, SP, Brazil in 2005 e 2011, respectively. He did sandwich doctoral stage, PDEE-CAPES, in the IST-Institute Superior Tecnico, Lisbon, Portugal in 2009. He is currently post-doctoral and professor of automation and control engineering in the IFSP - Federal Institute of Education, SP, Brazil. His research interests include Fuzzy controller, Artificial Neural Network, machine monitoring, diagnostic, electrical machines, FPGA and Industry 4.0 